complementary to another part of the Handbook (Series 4 (1) ) by Malone and Muskett, which described seventy-seven species of seed-borne fungi for purposes of recognition. Since the publication of Series 3, I have received 'working' copies of eleven further working sheets, an earnest that this most important international section of agricultural science is being expanded energetically.

\section{Liquid Inorganic Laser}

A LIQUID laser radiating at $\mathbf{1 . 0 6}$ microns and based on a solution of neodymium oxide in selenium oxychloride has been developed by Dr. Adam Heller and Dr. Alexander Lempicki, of General Electric and Telephone Laboratories Inc., according to the current issue of Applied Physics Letters. The device is a successor to an earlier laser based on a solution of a rare-earth in an organic chelating compound, the efficiency of which was limited by energy absorption by light atoms in the solvent. The working characteristics of the selenium oxychloride laser have not yet been determined, but pulses of 1 joule have so far been obtained with an input of energy measured as some hundreds of joules.

\section{Long Range Weather}

The Meteorological Office is cheerful if restrained about the success of its long range weather prediction service in its annual report for 1965 -the year that saw Professor B. J. Mason succeed Sir Graham Sutton as director-general (Annual Report on the Meteorological Office, H.M.S.O., 9s.). Long range forecasts for a period of thirty days ahead have been published twice a month for the past three years. On the basis of the first two years of the service, the Meteorological Office says that results have been slightly better than originally expected. According to the annual report for 1965, forecasts are assessed after the event by a panel of meteorologists, and "marks are given for the accuracy of forecasts of temperature, rainfall and additional information". Predicting temperature seems to be the easiest, with twenty-eight out of fifty forecasts ranking for the mark "good agreement". On rainfall, however, agreement between forecasts and reality was good on fourteen occasions, moderate on seventeen and deserving the description "little agreement" on nineteen occasions.

The long range forecasts are based on searches of records going back to the middle of the nineteenth century for analogous patterns of mean temperature and mean pressure in the northern hemisphere, and of successions of daily weather patterns in the British Isles. To predict for September 1966, for example, a search is made for weather patterns in August in earlier years which resemble that of August 1966. The long range weather forecasters are cheerful if they can find several years in which very similar August patterns are followed by September patterns which also resemble each other, and they then predict with confidence (though not necessarily with success) that September 1966 will be much the same as the earlier Septembers. Evidently this happy set of circumstances is not often repeated, however, and the report also points out that much will have to be done before the parameters which are really significant in this technique of analogous forecasting can be identified.
What might be called objective long range forecasting is reckoned to be an extremely distant prospect. Routine forecasts produced by computers have been available for nearly a year, and are said to be already as good as those produced by experienced forecasters. According to the report, the possibility of producing reliable computed forecasts for five days ahead is being seriously considered in the United States, and is also the motive for the proposed programme of World Weather Watch now being considered by the appropriate international organizations, and in which the Meteorological Office thinks it may be asked to play an important part.

\section{Academics make Maps}

Despite the fact that many European geological surveys rely largely on university personnel for their routine geological mapping, the sentinels of British geological surveying have long argued against such an arrangement. They have claimed that the system does not lead to the building up within the organization of the stock of experience and knowledge which the staff of a good survey needs. Moreover, they are at pains to point out that the survey man is a very different specimen from the academic geologist. Although the latter tends to follow his fancies and become a specialist, the professional surveyor must give-and be seen to give-his wholehearted and impartial attention to all facets of the geology which he encounters. In the past the Geological Survey of Great Britain has suffered somewhat from an inborn fear that a taste of academic bliss could entice away members of its staff.

Recently, with the advent of new geophysical and geochemical methods of surveying-most of which incur organization and finance beyond the reaches of many university departments-the boot has moved gradually over to the other foot. The Survey has become less churlish about entering into co-operative schemes with universities. The most recent contract to go to a university-and the first to deal with the production of a one inch geological map-speaks much for Sir James Stubblefield's efforts during his directorship of the Survey to foster relationships with universities. Through Prof. Scott Simpson's persuasiveness, the Department of Geology in the University of Exeter has received a contract from the Natural Environment Research Council on behalf of the Survey (now incorporated in the Institute of Geological Sciences). Over a period of 5 years, six postgraduate students will work under the joint supervision of the University of Exeter and the Geological Survey to re-survey the region covered by G.S.E.W. One Inch Sheet 339 (Teignmouth). This particular sheet was chosen because of the need to revise the Devonian and Carboniferous stratigraphy and structure of South Devon in the light of recent advances in the stratigraphy of South-West England, and because it is believed that the re-investigation of the Bovey Beds and the Haldon gravels will yield useful results. Although some of the ground has been re-surveyed on a scale of six inches to the mile, and although there were airborne surveys in the mid-fifties, the map itself has not been revised since 1909 .

Sir James Stubblefield has made it clear that the Geological Survey would be prepared to consider approaches from other university departments with the view of further joint projects. 